\title{
AVALIAÇÃO DE ALGUMAS CARACTERÍSTICAS FÍSICO-QUÍMICAS DA ÁGUA DO RIBEIRÃO SALGADINHO, NOVA XAVANTINA-MT
}

\section{EVALUATION OF PHYSICO-CHEMICAL CHARACTERISTICS OF WATER IN THE SALGADINHO STREAM, NOVA XAVANTINA-MT}

\section{Zillmer, T. A. ${ }^{1}$, Varella, R. F. ${ }^{2 \ddagger}$; Rossete A. N. ${ }^{3}$}

${ }^{1}$ Bióloga. End. Trav. Jundiaí n. 232, Nova Xavantina-MT. Fone: (66) 34381340/Fax: (66) 3438-1495, e-mail tatizillmer@hotmail.com

${ }^{2}$ Engenheiro Químico, Doutor em Geologia (UNB) na área de "Processamento de

Dados em Geologia e Análise Ambiental". (In memoriam)

${ }^{3}$ Geológo, Mestre em Geociências (UNICAMP) na área de "Planejamento

Ambiental, Mineração em Áreas Urbanas e Gestão dos Recursos Naturais".

\section{RESUMO}

As características dos ambientes aquáticos podem variar drasticamente em função da sazonalidade climática da região do cerrado, exigindo dos organismos aquáticos sua adaptação. Foram verificadas algumas características físico-químicas da água do Ribeirão Salgadinho, de $3^{\mathrm{a}}$ ordem, que se localiza na zona rural de Nova Xavantina, região sudeste de Mato Grosso. Três pontos foram escolhidos para a realização das coletas, estando um próximo a nascente, um tributário e o outro próximo à foz. As análises físico-químicas foram realizadas mensalmente no período de setembro de 2003 a setembro de 2004. Determinou-se nos pontos de coletas seis variáveis ambientais: turbidez, $\mathrm{pH}$, condutividade, dureza total e vazão. As variáveis ambientais analisadas apresentaram variações entre o período de seca e o chuvoso. Verificou-se aumento no valor da turbidez, resultante do escoamento superficial das chuvas e diminuição dos valores do $\mathrm{pH}$ e condutividade com o aumento da vazão.

Palavras-chave: Limnologia. Condutividade. pH. Dureza total. Ribeirão Salgadinho.

\begin{abstract}
The characteristics of aquatic environments may vary drastically due to the climatic seasonality of the Cerrado region, and this demands adaptations from the aquatic organisms. Some physico-chemical characteristics of the water in the
\end{abstract}


Salgadinho stream were analyzed. This 3 rd order stream is located in the rural area of Nova Xavantina, southern Mato Grosso state. Three sampling sites were determined, located near the stream headwaters, in a tributary and near the stream mouth. The analyese were conducted monthly between September/2003 and September/2004. At each sampling site, six environmental characteristics were analyzed: turbidity, $\mathrm{pH}$, conductivity, total water hardness and discharge. Turbidity values increased due to runoff in the rainy season, and $\mathrm{pH}$ and conductivity decreased as the stream discharge increased.

Keywords: Limnology. Conductivity. pH. Total water hardness. Salgadinho Rtream.

\section{INTRODUÇÃO}

O estudo da alteração da qualidade de água de sistemas "lóticos" é de extrema importância para registrar o comportamento desses sistemas em uma determinada época, o que reflete as condições ambientais da bacia hidrográfica. As características dos ambientes aquáticos podem variar drasticamente em função da sazonalidade da região do cerrado, exigindo dos organismos aquáticos a adaptação (JUNK, 1980).

Estudos realizados por Ferreira (2001) mostraram que com a ocupação humana dos Cerrados nos últimos quarenta anos, os processos impactantes sobre a região foram acelerados, devido ao aumento da densidade demográfica e a intensificação na ocupação da terra para pólos agropecuários.

Felizmente, a água ainda parece ser um recurso natural abundante no centrooeste, pois o potencial médio de água doce nos rios é de $878,7 \mathrm{~km}^{3} /$ ano $(16 \%$ do total nacional) e a sua disponibilidade social é a segunda maior do Brasil (93.357 $\mathrm{m}^{3}$ /hab/ano) (REBOUÇAS, 1997).

A grande disponibilidade de água significa que ela está presente não somente em quantidade adequada em uma dada região, mas também, que sua qualidade é satisfatória para suprir as necessidades de um determinado conjunto de seres vivos, sendo fundamental que os recursos hídricos apresentem condições físicas e químicas adequadas para a utilização pelos organismos (BRAGA et al., 2002).

As características de qualidade das águas derivam dos ambientes naturais e antrópicos onde se originam, circulam, percolam ou ficam estocadas (REBOUÇAS, 2002). A variação do nível d'água provoca uma série de transformações nas características limnológicas dos corpos d'água. Dentre as principais variáveis físicoquímicas que são utilizadas para medir alterações nos corpos d'água, destacam-se o $\mathrm{pH}$, a turbidez, a condutividade elétrica e a vazão.

A água é utilizada pelo homem para sua sobrevivência e melhoria de suas condições econômicas, sociais e comunitárias. A cada dia mais, o homem depende da disponibilidade das águas continentais, por isso, torna-se necessário o conhecimento da alteração da qualidade de água das bacias hidrográficas. 
Este trabalho tem por objetivo principal determinar as variações do $\mathrm{pH}$, vazão, condutividade elétrica e turbidez em diferentes pontos do Ribeirão Salgadinho, tendo como objetivo secundário identificar os fatores que estariam causando variações nas características físico-químicas da água do mesmo.

\section{MATERIAL E MÉTODOS}

\section{1. Área de Estudo}

O estudo foi realizado no Ribeirão Salgadinho, em Nova Xavantina - MT. De acordo com os critérios de ordenação dos cursos de água proposto por Horton (1932 apud GUERRA; CUNHA, 1995), sendo este um curso d'água de $3^{\circ}$ ordem. A sua nascente está localizada na fazenda Nossa Senhora do Carmo e a sua foz a uma altitude de $285 \mathrm{~m}$, à margem direita do Rio das Mortes, próximo ao centro da cidade de Nova Xavantina. A sua extensão total é de aproximadamente $12 \mathrm{~km}$, a sua porção perene se estende por $8 \mathrm{~km}$, sendo a região de cabeceira, na época da seca, intermitente (SILVA, 2001). Desde a nascente até a foz, o ribeirão atravessa propriedades particulares, sendo a maioria destas utilizadas para criação de gado.

O clima regional é do tipo tropical de savana (Aw), com duas estações bem marcadas, inverno seco, de maio a setembro; e verão chuvoso, de outobro a abril, que concentra mais de $80 \%$ da precipitação anual (ROSSETE; IVANAUSKAS, 2001). Foram escolhidos três pontos de coleta de forma a cobrir a área de drenagem de maneira representativa, para a realização das coletas mensais ao longo do percurso do ribeirão, sendo estes identificados como Ponto 1 (P1A e P1B) (nascente), Ponto 2 (P2) (tributário) e Ponto 3 (P3) (foz) (Figura 1).

Além das coletas de água, procedeu-se também a coleta de amostras de rochas filíticas pertencentes ao Grupo Cuiabá (BRASIL, 1981) para análise química, que conjuntamente com exposições de quartzito formam o substrato geológico predominante na microbacia, nos pontos P4, P5, P6 e P7 na região de cabeceira do ribeirão (Figura 1). 


\begin{tabular}{|l|r|}
\hline Recebido em: $25 / 08 / 2006$ & HOLOS Environment, v.7 n.2, 2007 - P. 126 \\
\hline Liberado para Publicação em: $23 / 11 / 2007$ & ISSN:1519-8634 (ON-LINE) \\
\hline
\end{tabular}

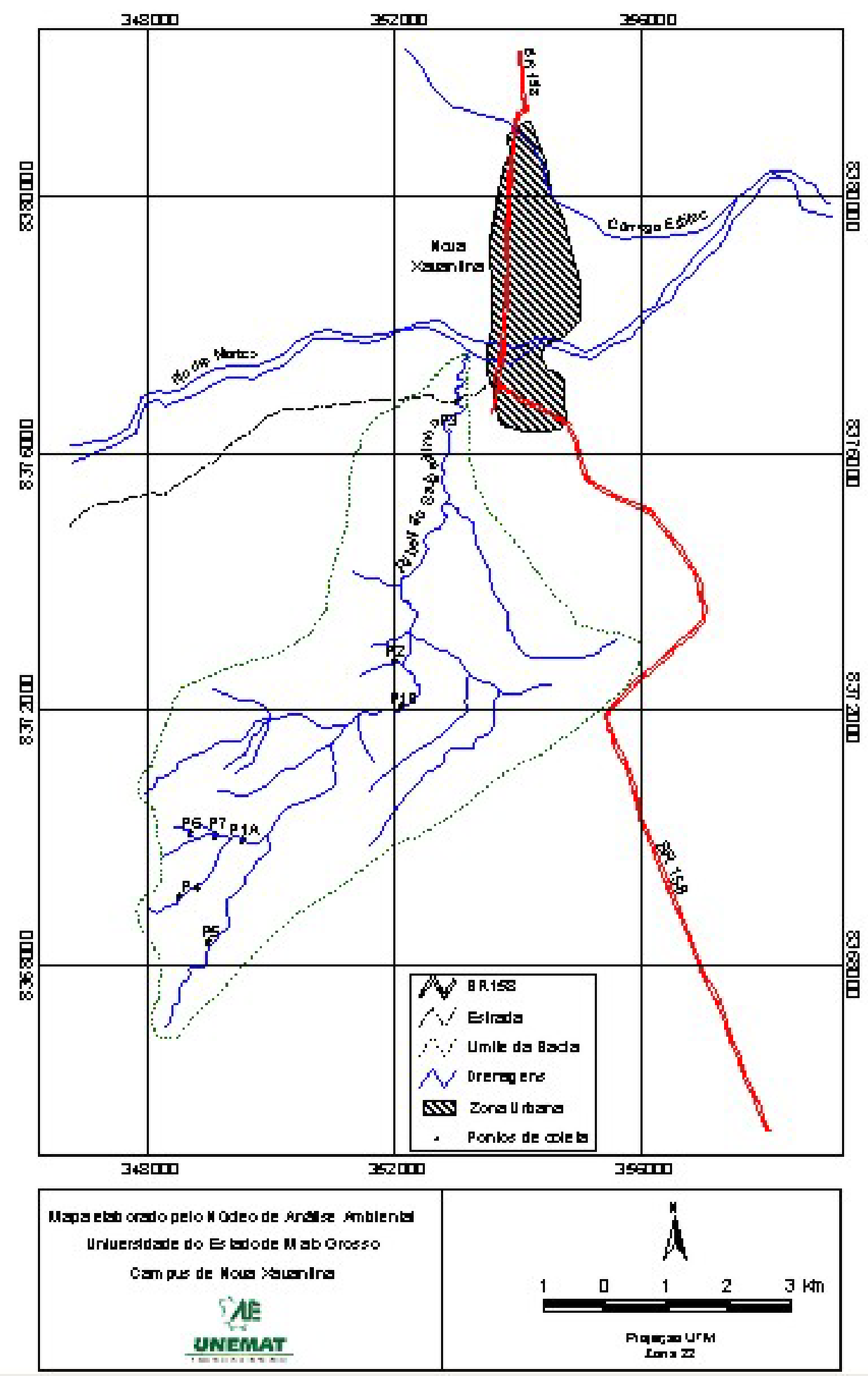

Figura 1. Localização dos pontos de coleta no Ribeirão Salgadinho, Nova Xavantina - MT.

As coletas de água foram realizadas mensalmente (dia dezessete de cada mês), no período da manhã, do mês de setembro de 2003 à agosto de 2004, em pontos prédeterminados e georeferenciados através da utilização de GPS utilizando o sistema de projeção Universal Transerva de Mercator zona 22. 
As amostras de água foram coletadas e armazenadas em frascos plásticos de $500 \mathrm{ml}$, previamente lavados com água do ribeirão, para posterior determinação, em laboratório, do $\mathrm{pH}$, turbidez, condutividade elétrica e dureza total.

$\mathrm{O} \mathrm{pH}$ foi medido pelo pHmetro (Quimis), a turbidez foi determinada em NTU (unidade nefelométrica) com auxilio do turbidímetro (Tecnopon TB 1000), a condutividade elétrica foi medida pelo condutivímetro, modelo C-702 Analion e a dureza total foi determinada pelo médoto titulométrico com EDTA, que consiste na titulação da dureza com a solucão de EDTA (sal dissódico), em $50 \mathrm{~mL}$ de água. Acrescenta-se na amostra $2 \mathrm{~mL}$ de solução tampão de Amônio e pulveriza com o Negro de Ericromo (AMERICAN PUBLIC HEALTH ASSOCIATION, 1995). Para o cálculo da dureza total emprega-se a seguinte equação;

\section{Dureza total, $\mathrm{mgCaCo}_{3} / \mathrm{L}=\underline{\mathrm{V} \text { EDTA }(\mathrm{mL}) \times \mathrm{FC} \times 1000 \mathrm{~mL} / \mathrm{L}}$ $\mathrm{V}$ amostra $(\mathrm{mL})$}

Onde: $\mathrm{FC}=\underline{\mathrm{mgCaCo}_{3}}$ mL EDTA

A vazão total do ribeirão foi medida no local de coleta, ponto 3 , que fica próximo à desembocadura do Ribeirão Salgadinho no Rio das Mortes. Para a medida da velocidade da água utilizou-se um "correntômetro" (MJP Geopacks).

A profundidade do canal foi medida ao longo de uma seção transversal (A) de 25 em 25 centímetros e a velocidade média da água (V) medida de 50 em 50 centímetros. Dessa forma, para o cálculo da descarga são necessárias a estimativa da velocidade média (metros por segundo) e a medição da área da seção molhada do canal (metros quadrados).

De acordo com Guerra e Cunha (1996), o fluxo fluvial é constituído pela descarga, podendo esta ser medida utilizando-se de diferentes métodos, mas, o mais conhecido deles emprega a equação:

$\mathrm{Q}=\mathrm{A}$. V, onde

$\mathrm{A}=$ área da seção transversal do canal;

$\mathrm{V}=$ velocidade média da água.

As amostras de rochas foram encaminhadas para o Laboratório de Geoquímica, do Instituto de Geociências, da Universidade de Brasília. A análise de elementos maiores foi determinada pelo espectômetro de emissão atômica com fonte de plasma (ICP-AES) com o espectômetro SPECTRO FVMO3.

Como forma de fornecer subsídios à interpretação dos dados limnológicos coletados em campo, foram obtidos dados climatológicos (precipitação pluviométrica) medidos de setembro de 2003 à agosto de 2004, junto à estação meteorológica situada no Parque Municipal Mário Viana, Nova Xavantina. 


\section{RESULTADOS E DISCUSSÃO}

\subsection{Precipitação Pluviométrica e Vazão}

As maiores precipitações pluviométricas mensais ocorreram no período de outubro de 2003 à abril de 2004, registrando no mês de janeiro a maior precipitação $(596,7 \mathrm{~mm})$. As menores precipitações foram notadas em setembro de 2003 e entre maio à agosto de 2004, chegando a zero em junho e agosto (Tabela 1). Para vazão, o maior fluxo de água $\left(1,507 \mathrm{~m}^{3} \mathrm{~s}^{-1}\right)$ no período de cheia foi observado no mês de janeiro. No período de seca, a menor vazão ocorreu no mês de setembro $\left(0,045 \mathrm{~m}^{3} \mathrm{~s}^{-}\right.$ ${ }^{1}$ ), visto que nesse período o fluxo de água depende do nível de água armazenada no lençol freático.

Tabela 1 - Dados hidrológicos e climatológicos do município de Nova XavantinaMT. (*) sem informação

\begin{tabular}{|c|c|c|c|c|c|c|}
\hline \multirow[b]{2}{*}{ Mês } & \multicolumn{3}{|c|}{ Temperatura do ar } & \multirow[b]{2}{*}{$\begin{array}{l}\text { Umidade } \\
\text { Relativa }\end{array}$} & \multirow[b]{2}{*}{$\begin{array}{l}\text { Precipitação } \\
\text { (mm) }\end{array}$} & \multirow[b]{2}{*}{$\begin{array}{l}\text { Vaxão } \\
\left(\mathrm{m}^{3} \mathrm{~s}^{-1}\right)\end{array}$} \\
\hline & Média & $\begin{array}{c}\text { Máxima } \\
\left.{ }^{\circ} \mathrm{C}\right)\end{array}$ & Mínima & & & \\
\hline setio3 & 26.4 & 36.1 & 18.8 & 59 & 26,4 & 0,045 \\
\hline outi03 & 26.4 & 34.0 & 21.0 & 72 & 92,8 & 0,102 \\
\hline nowi03 & 25.9 & 33.0 & 21.7 & 83 & 242,2 & 0,087 \\
\hline $\operatorname{dex} / 03$ & 25.9 & 33.0 & 21.5 & 84 & 171,6 & 0,130 \\
\hline jan 04 & 24.7 & 29.7 & 22.1 & 92 & 596,7 & 1,507 \\
\hline fevi04 & 24.8 & 30.4 & 21.6 & 89 & 271,0 & 1,075 \\
\hline $\operatorname{mar} / 04$ & 25.6 & 32.8 & 21.4 & 86 & 100,6 & 0,819 \\
\hline abr/04 & 25.7 & 32.5 & 20.8 & 86 & 125,8 & 1,075 \\
\hline maio/04 & 23.8 & 31.8 & 18.3 & 82 & 7,8 & $*$ \\
\hline juni04 & 21.1 & 31.9 & 13.8 & 76 & 00 & 0,376 \\
\hline Jull04 & 22.4 & 32.4 & 14.0 & 73 & 7,1 & 0,185 \\
\hline ago/04 & 22.8 & 35.4 & 13.5 & 58 & 00 & 0,112 \\
\hline
\end{tabular}

Além da precipitação influenciar na qualidade de um corpo d'água, é um fenômeno meteorológico que influencia diretamente a vazão. Entretanto, especialmente no meio rural, é difícil estabelecer uma relação direta entre precipitação e qualidade de água, uma vez que diferentes intensidades de precipitação e a interação desta precipitação com o uso e ocupação das terras (FRITZSONS et al., 2003) estabelecem diversos níveis de impactos no solo que deflagram processos erosivos de diversos graus.

Como se pode ver, a maior fonte de variação da vazão de uma microbacia hidrográfica é a precipitação e com a variação da vazão, ocorre uma série de transformações nas características limnológicas dos corpos d'água que promovem um aumento ou diminuição nos valores das variáveis.

Fritzsons et al. (2003) ressaltam que a influência da precipitação na vazão deve ser analisada dentro de uma seqüência de eventos pluviométricos, uma vez que o grau 
de saturação do solo e do sistema freático influenciam diretamente na taxa de escoamento superficial. Desse modo, a vazão parece ser a variável mais adequada para a avaliação de um corpo de água quando comparado a pluviometria, uma vez que a qualidade das águas de um rio pode ser alterada com a variação do fluxo.

\subsection{Potencial Hidrogeniônico $(\mathrm{pH})$}

Conforme se pode ver, na Tabela 2, os valores do $\mathrm{pH}$ oscilaram entre 5,39 e 7,77. Para Esteves (1998), as medidas do $\mathrm{pH}$ podem ser influenciadas por inúmeros fatores tais como: concentração de íons $\mathrm{H}^{+}$originados da ionização do ácido cabônico que gera valores baixos do $\mathrm{pH}$ e das relações de íons de carbonato com a molécula de água, que eleva os valores do $\mathrm{pH}$ para faixa alcalina. $\mathrm{O}$ mesmo autor ainda lembra, que a grande maioria dos corpos d'água continentais tem $\mathrm{pH}$ que varia entre 6 e 8 , no entanto, pode-se encontrar ambientes ácidos ou mais alcalinos.

Tabela 2 - Valor mensal do potencial hidrogeniônico $(\mathrm{pH})$ no Ribeirão Salgadinho MT.

\begin{tabular}{llll}
\hline Pontos & Ponto l & Ponto 2 & Ponto 3 \\
\hline Mês & & & \\
\hline set:03 & 7,14 & 6,60 & 7,68 \\
\hline out:03 & 6,92 & 6,28 & 7,77 \\
\hline novi03 & 7,16 & 6,59 & 7,77 \\
\hline dez:03 & 6,15 & 6,12 & 6,55 \\
\hline jan:04 & 6,00 & 6,22 & 6,48 \\
\hline fevi04 & 6,38 & 5,99 & 6,75 \\
\hline Mari04 & 6,85 & 6,33 & 6,90 \\
\hline abri04 & 5,83 & 5,68 & 6,38 \\
\hline maio/04 & 5,66 & 5,39 & 6,09 \\
\hline jun:04 & 6,46 & 6,14 & 7,34 \\
\hline jul:04 & 6,25 & 5,82 & 7,33 \\
\hline ago:04 & 6,99 & 7,47 & 7,44 \\
\hline
\end{tabular}

O processo de decomposição da matéria orgânica reduz o $\mathrm{pH}$ pelo aumento da concentração de gás carbônico que, ao dissolver-se na água, forma o ácido carbônico. Esse fato não se relaciona com o observado em alguns estudos dos sistemas hídricos do município de Nova Xavantina, como no córrego Bacaba (BLEICH, 2002) e no córrego Estilac (MINGOTE, 2004), e também com o observado no Ribeirão Salgadinho, pois no período de seca, onde há maior concentração de matéria orgânica, os valores do $\mathrm{pH}$ estiveram mais elevados que os valores registrados no período de cheia.

Nas amostras de rochas analisadas do Ribeirão Salgadinho, Tabela 3, pode-se verificar que o $\mathrm{CaO}$ e $\mathrm{MgO}$ possuem teores médios de 2,5\% e 2,4\% respectivamente, valores estes considerados elevados quando comparados com os obtidos por Biondi e 
Marczynski (2004), que foram de 0,24\% $\mathrm{MgO}$ e $0,07 \% \mathrm{CaO}$ e Meneses et al. (2001), com $0,92 \% \mathrm{MgO}$ e $0,14 \% \mathrm{CaO}$ em rochas filítcas.

Sendo assim, no intemperismo químico provocado pela água sobre as rochas pode haver liberação de $\mathrm{Ca}$ e $\mathrm{Mg}$, na corrente d'água e, conseqüentemente, esses elementos em contato com a água transformam-se em carbonatos de cálcio e de magnésio que tendem a elevar o $\mathrm{pH}$, uma vez que esses elementos possuem propriedades básicas. Entretanto, no período de chuva com o escoamento superficial da água da chuva pode haver menor concentração destes materiais, o que tende a diminuir o $\mathrm{pH}$.

Com o aumento da vazão nota-se um tendência na queda nos valores do $\mathrm{pH}$. Pode-se afirmar que o aumento da vazão traz como conseqüência uma maior diluição dos íons presentes na água fazendo com que ocorra uma diminuição nos valores do pH. Na tentativa de demonstrar este comportamento, ajustou-se aos dados obtidos durante o período de coleta, uma curva de decaimento exponencial, que revelou coeficiente de correlação $\left(\mathrm{r}^{2}\right)$ de 0,85 (Figura 3 ), o que denota uma relação acentuada entre o aumento da vazão e diminuição do $\mathrm{pH}$.

Os pontos ( $\mathrm{P} 1$ e $\mathrm{P} 2$, em abril e maio, e $\mathrm{P} 2$, em julho) possuem o $\mathrm{pH}$ abaixo de 6,0, o que segundo o CONAMA (BRASIL, 2005) torna a água nestas condições imprópria para consumo humano. O Ribeirão Salgadinho possui águas ácidas na estação chuvosa e seu menor valor foi 5,39, em maio no P2.

Tabela 3 - Dados da composição química de amostras de rochas filíticas do grupo Cuiabá no Estado de Mato Grosso, Ribeirão Salgadinho, Nova Xavantina. PF="perda ao fogo".

\begin{tabular}{|c|c|c|c|c|c|c|c|}
\hline Amostra & P4 & P5 & P6 & P7 & Maior & Menor & Média \\
\hline \multicolumn{8}{|l|}{ Substância } \\
\hline $\begin{array}{ll}\mathrm{SiO}_{2} & (\%)\end{array}$ & 57,1 & 52,8 & 58,1 & 63,2 & 63,2 & 52,8 & 57,8 \\
\hline $\mathrm{TiO}_{2} \quad(\%)$ & 0,84 & 0,75 & 0,92 & 0,79 & 0,92 & 0,75 & 0,82 \\
\hline $\mathrm{Al}_{2} \mathrm{O}_{3} \quad(\%)$ & 16,09 & 14,08 & 19,01 & 17,07 & 19,01 & 14,08 & 16,5 \\
\hline $\mathrm{Fe}_{2} \mathrm{O}_{3} \quad(\%)$ & 5,27 & 20,76 & 8,39 & 7,91 & 20,76 & 5,27 & 10,9 \\
\hline $\begin{array}{l}\mathrm{MgO} \quad(\%) \\
\end{array}$ & 1,16 & 5,13 & 2,32 & 1,11 & 5,13 & 1,11 & 2,4 \\
\hline$\overline{\mathrm{CaO}}$ & 8,4 & 0,73 & 0,64 & 0,35 & 8,4 & 0,35 & 2,5 \\
\hline $\begin{array}{ll}\mathrm{MrO} & (\%)\end{array}$ & 0,36 & 0,17 & 0,09 & 0,05 & 0,36 & 0,05 & 0,17 \\
\hline $\mathrm{Na_{2 }} \mathrm{O}$ & 0,78 & 0,18 & 0,76 & 0,53 & 0,78 & 0,18 & 0,56 \\
\hline $\mathrm{K}_{2} \mathrm{O}$ & 4,66 & 0,25 & 3,84 & 3,41 & 4,66 & 0,25 & 3,04 \\
\hline $\mathrm{P}_{2} \mathrm{O}_{5} \quad(\%)$ & 0,05 & 0,21 & 0,09 & 0,1 & 0,21 & 0,05 & 0,11 \\
\hline PF $\quad(\%)$ & 5,17 & 5,34 & 6,64 & 5,78 & 6,64 & 5,34 & 5,73 \\
\hline TOTAL $(\%)$ & 99,85 & 100,34 & 100,82 & 100,27 & & & \\
\hline
\end{tabular}




\subsection{Turbidez}

O mês de janeiro teve maior precipitação pluviométrica, e, conseqüentemente, maior turbidez nos P1 e P3, respectivamente 16,6 NTU e 111,0 NTU (Tabela 4), o que pode ser explicado pelo aumento da máteria em suspensão que a água carrega para dentro do ribeirão.

O P1 possui características diferentes dos outros dois pontos, por ter maior turbidez no período de seca, no mês de outubro (164,0 NTU), e também a menor turbidez, no mês de agosto, 2,58 NTU (Tabela 4). Esse alto valor de turbidez no período de seca, pode ser elucidado pelo grande acúmulo de matéria orgânica em decomposição proveniente da vegetação no $\mathrm{P} 1 \mathrm{~B}$, o que contribuí para o aumento da quantidade de partículas suspensas. Este fato também foi observado por Mingote (2004) no córrego Estilac. No entanto, no período de chuva, os valores de turbidez atingiram 163,0 NTU no mês de fevereiro. Em janeiro houve uma queda no valor de turbidez, que foi medida no P1A, provavelmente devido a diminuição da quantidade de matéria orgânica. Em fevereiro o valor torna a subir devido as fortes chuvas que carream material para dentro do ribeirão. Esteves (1998), ressalta que os principais responsáveis pela turbidez da água são as particulas suspensas (bactérias, detritos orgânicos e inorgânicos etc.) e em menor proporção os compostos dissolvidos.

Tabela 4 - Valor mensal de turbidez (NTU) no Ribeirão Salgadinho, Nova Xavantina - MT. (*) sem informação.

\begin{tabular}{lccc}
\hline Pontos & Ponto I & Ponto 2 & Ponto 3 \\
\hline Mês & & & \\
\hline Set:03 & 163,00 & 0,84 & 1,16 \\
\hline out:03 & 164,00 & $*$ & 11,10 \\
\hline novi03 & 150,00 & 1,19 & 4,50 \\
\hline dex:03 & 143,00 & 11,30 & 8,13 \\
\hline jan:04 & 65,00 & 16,60 & 11,00 \\
\hline Fevi04 & 163,00 & 6,85 & 17,50 \\
\hline mari04 & 0,70 & 0,22 & 0,80 \\
\hline abri04 & 18,5 & 9,96 & 21,60 \\
\hline maio/04 & $*$ & 0,87 & 6,54 \\
\hline jun:04 & 18,5 & 0,13 & 8,00 \\
\hline Jul04 & $*$ & 0,59 & 0,83 \\
\hline ago:04 & 2,58 & 1,27 & 0,80 \\
\hline
\end{tabular}

Segundo Fritizsons et al. (2003), em termos ambientais, a principal conseqüência da alteração da cor e da turbidez num corpo d'água é a redução da penetração da luz solar e a conseqüente diminuição da taxa de fotossíntese, o que prejudica a oxigenação do meio principalmente em águas paradas ou mesmo em rios de baixa turbulência. Braga et al. (2002), ressaltam que o aumento da turbidez na 
água reduz a taxa de fotossíntese e prejudica a procura de alimento para algumas espécies.

A turbidez dos corpos d'água é particularmente alta em regiões com solos erodíveis, onde a precipitação pluviométrica pode carrear partículas de argila, silte, fragmentos de rocha e óxidos metálicos do solo. Grande parte das águas de rios brasileiros é naturalmente turva em decorrência das características geológicas das bacias de drenagem e devido à ocorrência de fortes chuvas (VON SPERLING, 1998).

A turbidez tende a se elevar quando a vazão aumenta, exeção no P1. O coeficiente de correlação $\left(r^{2}\right)$ da curva de ajuste de crescimento exponencial da turbidez com a vazão foi de 0,97 , melhor que os obtidos para $\mathrm{pH}$ e condutividade (Figura 3). Assim, a tendência é que quanto maior a vazão, maior a turbidez, uma vez que, os principais responsáveis pela turbidez da água são principalmente as partículas suspensas (bactérias, fitoplâncton, detritos orgânicos e inorgânicos). Este aumento da turbidez com a vazão é justificado pelo carreamento de maiores quantidades de partículas orgânicas e inorgânicas do escoamento superficial e do leito do Ribeirão Salgadinho na ocasião de altas vazões.

\subsection{Condutividade Elétrica e Dureza Total da Água}

Os valores da condutividade elétrica mostraram um nítido padrão de variação decorrente do ciclo hidrológico. Pode-se verificar na Tabela 5 que na época seca houve aumento da condutividade, chegando a $414,0 \mu \mathrm{S} \mathrm{cm}^{-1}$ no P1, enquanto que, no período de maior precipitação a condutividade diminuiu em todos os pontos, chegando a $44,5 \mu \mathrm{S} \mathrm{cm}^{-1}$ no P3.

Tabela 5 - Valor mensal da condutividade elétrica $\left(\mu \mathrm{S} \mathrm{cm}^{-1}\right)$ do Ribeirão Salgadinho, Nova Xavantina - MT.

\begin{tabular}{lccc}
\hline Pontos & Ponto l & Ponto 2 & Ponto 3 \\
\hline Mês & & & \\
\hline set:03 & 414,0 & 189,0 & 330,0 \\
\hline out:03 & 358,0 & 155,0 & 298,0 \\
\hline novi03 & 354,0 & 178,0 & 305,0 \\
\hline dex/03 & 144,0 & 159,0 & 250,0 \\
\hline jan:04 & 45,0 & 66,4 & 44,5 \\
\hline fevi04 & 53,2 & 58,2 & 75,8 \\
\hline mar:04 & 59,9 & 52,8 & 87,2 \\
\hline abri04 & 78,6 & 63,5 & 112,2 \\
\hline maio/04 & 85,7 & 60,8 & 140,9 \\
\hline jun:04 & 74,0 & 63,4 & 159,3 \\
\hline jul04 & 93,3 & 64,7 & 179,9 \\
\hline ago:04 & 292,0 & 97,0 & 231,0 \\
\hline
\end{tabular}


Para Feitosa e Manoel Filho (2000) e Esteves (1998), a condutividade da água tende a aumentar com a elevação da temperatura e com a maior concentração de íons dissolvidos.

Os íons mais diretamente responsáveis pelos valores de condutividade elétrica são os chamados macronutrientes como: cálcio, magnésio, potássio, sódio, carbonato, sulfato, cloreto, etc., enquanto que nitrato, nitrito e especialmente ortofosfato têm pouca influência, e o íon amônio pode ter influência somente em altas concentrações (ESTEVES, 1998).

Os três maiores mecanismos controladores da salinidade nas águas superfíciais são a predominância rochosa, a precipitação atmosférica e os processos de evaporação-precipitação. A importância de cada um destes mecanismos é dependente de fatores geográficos, geológicos e climáticos que alteram as concentrações dos cátions $\left(\mathrm{Ca}^{++}, \mathrm{Mg}^{++}, \mathrm{Na}^{+}\right.$e $\left.\mathrm{K}^{+}\right)$e ânions $\left(\mathrm{HCO}_{3}^{-}, \mathrm{Cl}^{-}\right.$e $\left.\mathrm{SO}_{4}{ }^{2-}\right)$ principais (LEITE; FONSECA, 2002).

Os valores de condutividade elétrica da água do Ribeirão Salgadinho são muito elevados, principalmente durante a estação seca, quando comparados com os valores obtidos por Mingote (2004) no córrego Estilac $\left(<60,0 \mu \mathrm{S} \mathrm{cm}^{-1}\right)$ e por Bleich (2002) no córrego Bacaba $\left(<114,0 \mu \mathrm{S} \mathrm{cm}^{-1}\right)$.

A diminuição da condutividade elétrica no Ribeirão Salgadinho no período de chuva pode ser causada pela diluição de íons decorrente do aumento do volume d'água.

Como já mencionado, as rochas filíticas que constituem o ribeirão possuem elevados valores médios dos óxidos de $\mathrm{Mg}(2,40 \%)$ e $\mathrm{Ca}(2,50 \%)$, que são superiores aos encontrados por Biondi e Marczynski (2004) (0,24\% $\mathrm{MgO}$ e $0,07 \%$ $\mathrm{CaO})$ e Meneses et al. (2001) $(0,92 \% \mathrm{MgO}$ e $0,14 \% \mathrm{CaO})$, em amostras de filitos. Nas análises de água do ribeirão verificou-se que a condutividade elétrica da água tende a aumentar com o aumento da dureza total (Figura 2). Isso é reflexo da riqueza do substrato geológico, em íons de cálcio e magnésio, que são liberados na corrente d'água. Estudos realizados por Ranzini e Lima (2002), em microbacias reflorestadas com eucalipto no Vale do Paraíba, as saídas de $\mathrm{Ca}$ e $\mathrm{Mg}$ são maiores que as entradas via precipitação, comprovando a riqueza do sustrato. Souza e Tundisi (2000), complementam que rios com substrato geológico muito pobre possuem baixa condutividade elétrica e concentrações iônicas nas suas águas. O coeficiente de correlação de 0,98 obtido no ajuste da curva de crescimento exponencial aos dados de condutividade, indica que a variação da condutividade está diretamente relacionada à variação da dureza total.

A variação entre condutividade elétrica da água do Ribeirão Salgadinho e a vazão, pode ser visualizada na Figura 3, observando-se que o comportamento desta variável é semelhante ao do $\mathrm{pH}$. Neste caso o coeficiente de correlação obtido no ajuste de curva de decaimento exponencial aos dados de condutividade foi de 0,90. Bleich (2002), observou o mesmo tipo de comportamento entre condutividade e vazão no córrego Bacaba. 
Sendo assim, no período de chuva, devido à entrada de material alóctone incluindo íons, poderia se esperar o aumento da condutividade elétrica, porém, a maior entrada de água resulta numa diminuição das concentrações iônicas e, conseqüentemente, na condutividade elétrica, caracterizando um efeito de diluição dos solutos. $\mathrm{O} \mathrm{CaO}$ e o $\mathrm{MgO}$ são os principais responsáveis pelas variações da condutividade elétrica da água do Ribeirão Salgadinho.

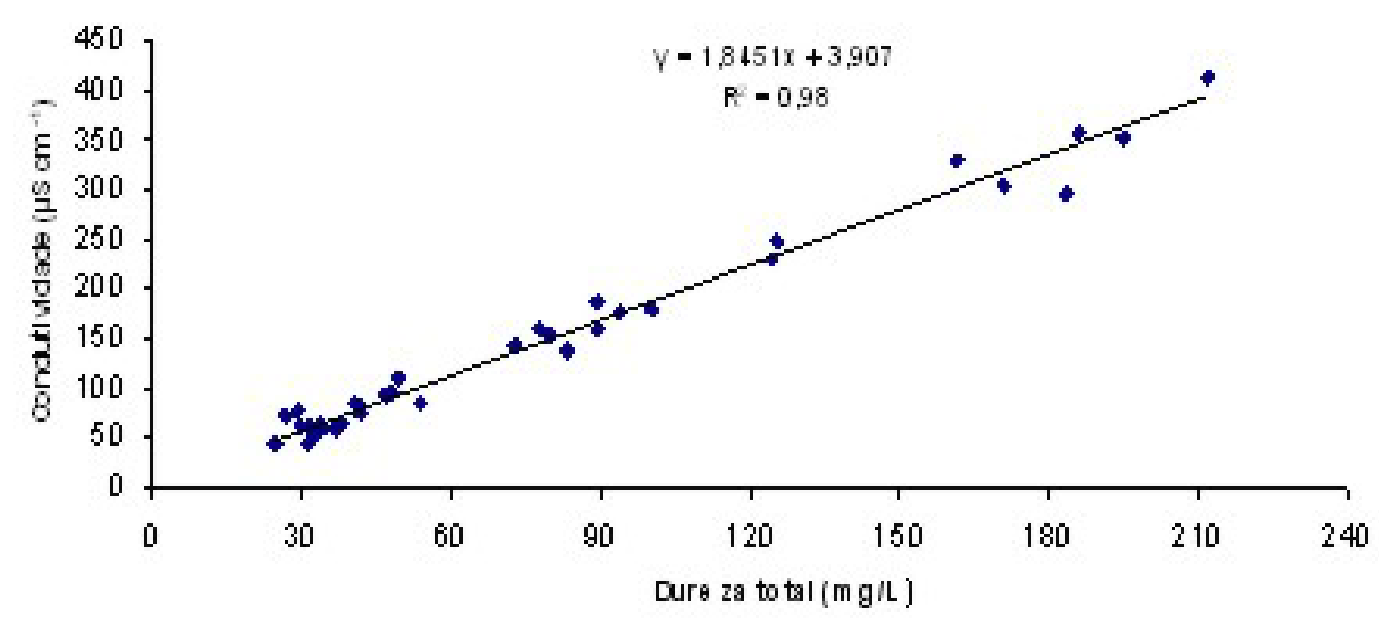

Figura 2. Variação da condutividade elétrica em função da dureza total, no Ribeirão Salgadinho em Nova Xavantina - MT. 


\begin{tabular}{|l|r|}
\hline Recebido em: $25 / 08 / 2006$ & HOLOS Environment, v.7 n.2, 2007 - P. 135 \\
\hline Liberado para Publicação em: $23 / 11 / 2007$ & ISSN:1519-8634 (ON-LINE) \\
\hline
\end{tabular}

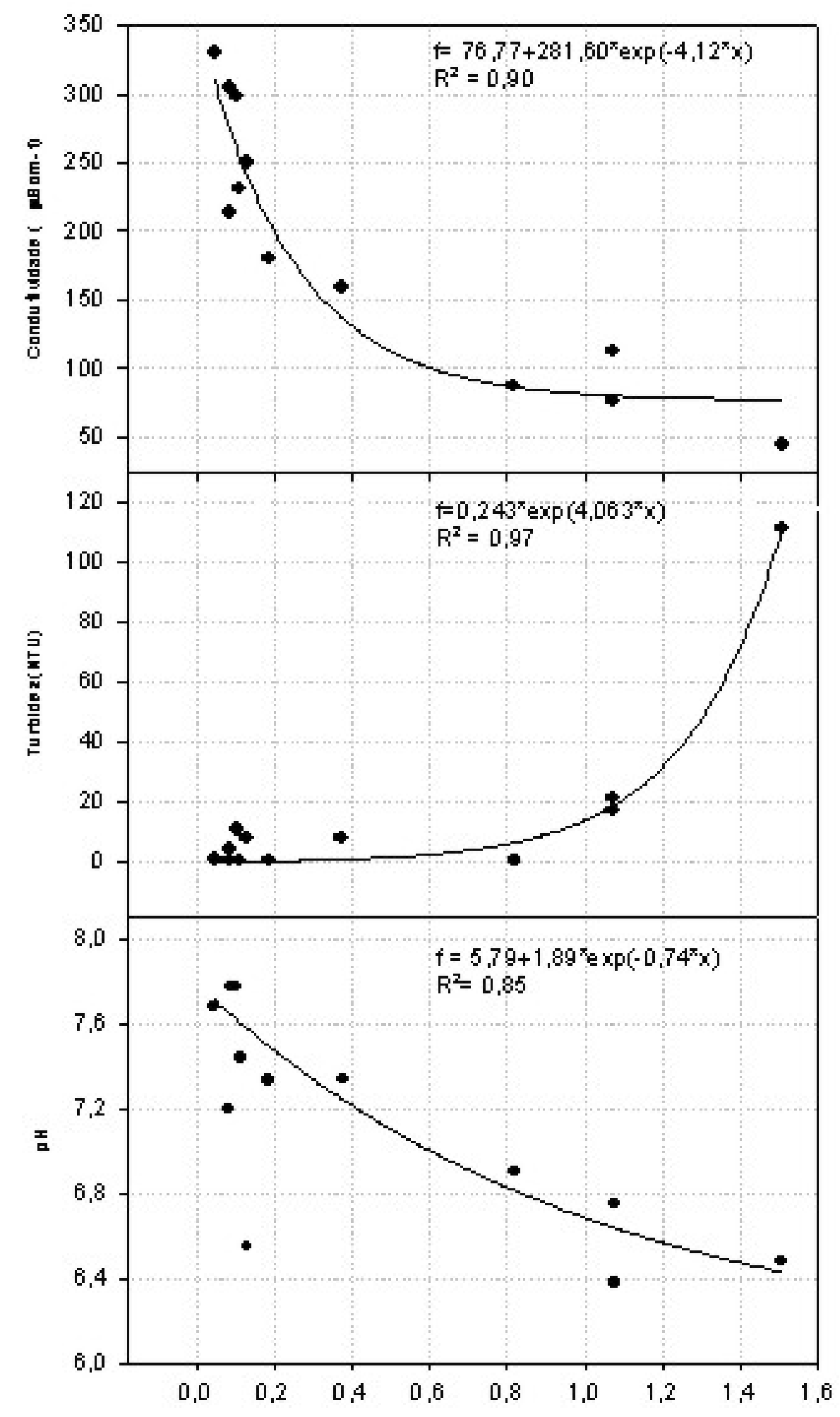

Figura 3. Variação da condutividade, turbidez e pH em função da vazão no Ribeirão Salgadinho no P3, em Nova Xavantina - MT. 


\section{CONCLUSÃO}

O pH da água do Ribeirão Salgadinho é ácido na estação chuvosa.

A variação dos valores da condutividade elétrica da água foi semelhante ao do pH. Enquanto, os valores de condutividade e do $\mathrm{pH}$ da água aumentam com a diminuição da vazão, os valores de turbidez aumentam exponencialmente com o aumento da vazão.

As variáveis $\left(\mathrm{pH}\left(\mathrm{r}^{2} 0,85\right)\right.$, condutividade $\left(\mathrm{r}^{2} 0,90\right)$ e turbidez $\left.\left(\mathrm{r}^{2} 0,97\right)\right)$ apresentaram boa correlação com a vazão.

A condutividade elétrica apresentou grau de correlação $(0,98)$ melhor em função da dureza total.

\section{REFERÊNCIAS}

AMERICAN PUBLIC HEALTH ASSOCIATION. Standard methods for the examination of water and wastewater. $14^{\text {th }} \mathrm{ed}$. New York, 1995.

BIONDI, J. C., MARCZYNSKI, S. Caracterização física e química dos filitos Açungui (PR) visando sua utilização pela indústria cerâmica. Cerâmica, São Paulo, v. 50, n. 313, p. 21-32, 2004. Disponível em: http://www.scielo.br/scielo.php?script=sci arttext\&pid= S036669132004000100004

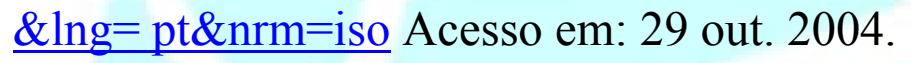

BLEICH, M. E. Características limnológicas do córrego Bacaba, Nova Xavantina-MT. 2002. 44 f. Trabalho de Conclusão de Curso (Graduação em Ciências Biológicas) - Universidade do Estado de Mato Grosso, Nova Xavantina.

BRAGA, B.; BARROS, M. T. L.; CONEJO, J. G. L.; EIGER, S.; HESPANHOL, I.; JULIANO, N. M. A.; NUCCI, N. L. R.; PORTO, M. F. A.; VERAS JR, M. S. Introdução à engenharia ambiental. São Paulo: Prentice Hall, 2002.

BRASIL. Ministério das Minas e Energia. Secretaria Geral Projeto RADAMBRASIL. Folha SD 22. Goiás: geologia, geomorfologia, pedologia, vegetação, uso potencial da terra. Brasília, 1981.

BRASIL. Ministério do Meio Ambiente. Conselho Nacional do Meio Ambiente. Resolução n. 357, de 17 de março de 2005: classificação dois corpos de água: Dispõe sobre a classificação dos corpos de água e diretrizes ambientais para o seu enquadramento, bem como estabelece as condições e padrões de lançamento de efluentes, e dá outras providências. Disponível em: 
http://www.aesa.pb.gov.br/legislacao/resolucoes/conama/357_05_classificacao_corp os agua.pdf Acesso em: 31 jan. 2007.

ESTEVES, F. A. Fundamento da limnologia. 2. ed. Rio de Janeiro: Interciência, FINEP, 1998.

FEITOSA, F. A. C.; MANOEL FILHO, J. Hidrologia: conceitos e aplicações. 2. ed. Fortaleza: CPRM-REFO, LABHID-UFPE, 2000.

FERREIRA, J. C. V. Mato Grosso e seus municípios. Cuiabá: Buriti, 2001.

FRITZSONS, E.; HINDI, E. C.; MANTOVANI, L. E.; RIZZI, N. E. As alterações da qualidade de água do rio Capivari com o deflúvio: um instrumento de diagnóstico de qualidade ambiental. Engenharia Sanitária e Ambiental, Rio de Janeiro, v. 8, n. 4, p. 239-248, 2003.

GUERRA, A J. T.; CUNHA, S. B. Geomorfologia: uma atualização de bases e conceitos. 2. ed. Rio de Janeiro: Bertrand Brasil, 1995.

GUERRA, A J. T.; CUNHA, S. B. Geomorfologia: exercícios, técnicas e aplicações. 3. ed. Rio de Janeiro: Bertrand Brasil, 1996.

JUNK, W. J. Áreas inundáveis: um desafio para a limnologia. Acta Amazônica, Manaus, v. 10, n. 4, p. 775-7795. 1980.

LEITE, F. P.; FONSECA, O. J. M. Variação espacial e temporal de parâmetros ambientais da lagoa Caconde, Orósio, RS. Acta Limnológica Brasiliensis, Botucatu, v. 14, n. 2, p. 39-50, 2002.

MENESES, P. R.; MADEIRA NETO, J. C.; PONTARA, R. C.; SILVA, F. H. F. Comportamento da reflectância espectral de filitos carbonosos mineralizados em ouro. Revista Brasileira de Geociências, Brasília, v. 31, n. 1, p. 83-88, 2001. Disponível em: http://www.sbgeo.org.br/rgb/vol31_down/3101/3101083.pdf Acesso em: 31 jan. 2007.

MINGOTE, G. Situação da água do Córrego Estilac, Nova Xavantina-MT. 2004. 40 f. Trabalho de Conclusão de Curso (Graduação em Ciências Biológicas) Universidade do Estado de Mato Grosso, Nova Xavantina.

RANZINI, M.; LIMA, W P. Comportamento hidrológico, balanço de nutrientes e perdas de solo em duas microbacias reflorestadas com Eucalyptus, no Vale do Paraíba, SP. Scientia Forestalis, Piracicaba, n. 61, p. 144-159, 2002. 
REBOUÇAS, A. C. (Org.). Panoramas da degradação do ar, da água doce e da terra no Brasil. Rio de Janeiro: Academia Brasileira de Ciências, 1997.

REBOUÇAS, A. C. Água doce no mundo e no Brasil. In: . Águas doces do Brasil: capital ecológico, uso e conservação. 2 ed. São Paulo: Escrituras, 2002. p. 0137.

ROSSETE, A. N.; IVANAUSKAS, N. M. Levantamento do meio físico e da vegetação do Parque Bacaba. Relatório final. Nova Xavantina: UNEMAT, 2001.

SILVA, C. A. Levantamento e morfometria de camarões (CORIDEA DANAE, 1852) do Riacho Salgadinho em Nova Xavantina-MT. 2001. 30 f. Trabalho de Conclusão de Curso (Graduação em Ciências Biológicas) - Universidade do Estado de Mato Grosso, Nova Xavantina.

SOUZA, A. D. G.; TUNDISI, J. G. Hidrogeochemical comparative study of the Jaú and Jacaré-Guaçu River watersheds, São Paulo, Brazil. Revista Brasileira de Biologia, São Carlos, v. 60, n. 4, p. 563-570, 2000. http://dx.doi.org/10.1590/S0034$\underline{71082000000400004}$

VON SPERLING, E. Qualidade de água em atividades de mineração. In: DIAS, L. E.; MELO, J. W. V. (Org.). Recuperação de águas degradadas. Viçosa: Sociedade Brasileira de Áreas Degradadas, 1998. p. 95-105. 